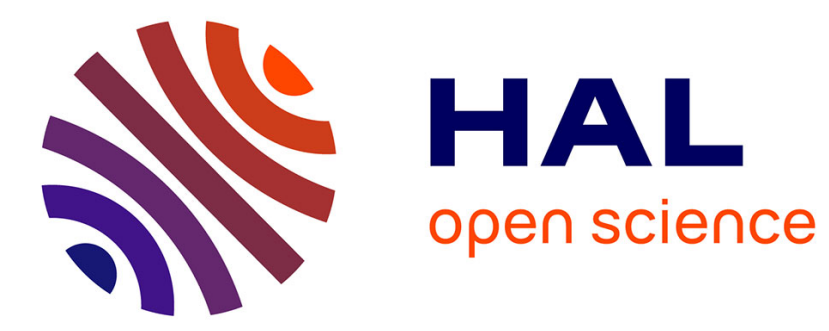

\title{
CFD modelling of two-phase stirred bioreaction systems by segregated solution of the Euler-Euler model
}

\author{
Mohammed Elqotbi, S.D. Vlaev, Ludovic Montastruc, Iordan Nikov
}

\section{To cite this version:}

Mohammed Elqotbi, S.D. Vlaev, Ludovic Montastruc, Iordan Nikov. CFD modelling of two-phase stirred bioreaction systems by segregated solution of the Euler-Euler model. Computers \& Chemical Engineering, 2013, vol. 48, pp. 113-120. 10.1016/j.compchemeng.2012.08.005 . hal-00919308

\section{HAL Id: hal-00919308 https://hal.science/hal-00919308}

Submitted on 16 Dec 2013

HAL is a multi-disciplinary open access archive for the deposit and dissemination of scientific research documents, whether they are published or not. The documents may come from teaching and research institutions in France or abroad, or from public or private research centers.
L'archive ouverte pluridisciplinaire HAL, est destinée au dépôt et à la diffusion de documents scientifiques de niveau recherche, publiés ou non, émanant des établissements d'enseignement et de recherche français ou étrangers, des laboratoires publics ou privés. 


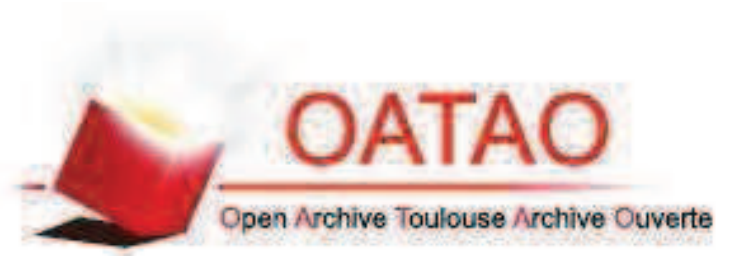

\section{Open Archive Toulouse Archive Ouverte (OATAO)}

OATAO is an open access repository that collects the work of Toulouse researchers and makes it freely available over the web where possible.

This is an author-deposited version published in: http://oatao.univ-toulouse.fr/ Eprints ID: 9919

To link to this article : DOI:10.1016/j.compchemeng.2012.08.005

URL: http://dx.doi.org/10.1016/j.compchemeng.2012.08.005

\section{To cite this version:}

Elqotbi, Mohammed and Vlaev, S.D. and Montastruc, Ludovic and Nikov, Iordan CFD modelling of two-phase stirred bioreaction systems by segregated solution of the Euler-Euler model. (2013) Computers \& Chemical Engineering, vol. 48. pp. 113-120. ISSN 0098-1354 


\title{
CFD modelling of two-phase stirred bioreaction systems by segregated solution of the Euler-Euler model
}

\author{
M. Elqotbi ${ }^{\text {a }}$ S.D. Vlaev ${ }^{\text {b,* }}$, L. Montastruc ${ }^{\mathrm{a}, \mathrm{c}}, \mathrm{I}_{\text {. Nikov }}^{\mathrm{a}}$

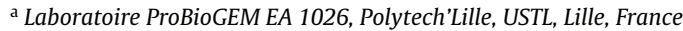 \\ b Bulgarian Academy of Sciences Institute of Chemical Engineering, Acad. G. Bonchev Str. Bl. 103, 1113 Sofia, Bulgaria \\ ${ }^{\mathrm{c}}$ LGC-CNRS-INPT, Université de Toulouse, 4, Allée Emile Monso, BP 84234, 31432 Toulouse, France
}

Keywords:

Modelling

CFD

Gluconic acid

Stirred reactor

Viscosity effects

$K_{L} a$

\begin{abstract}
A B S T R A C T
An advanced study of a bioreactor system involving a Navier-Stokes based model has been accomplished. The model allows a more realistic impeller induced flow image to be combined with the Monod bioreaction kinetics reported previously. The time-course of gluconic acid production by Aspergillus niger strain is simulated at kinetic conditions proposed in the literature. The simulation is based on (1) a stepwise solution strategy resolving first the fluid flow field, further imposing oxygen mass transfer and bioreaction with subsequent analysis of flow interactions, and (2) a segregated solution of the model replacing the multiple iterations per grid cell with single iterations. The numerical results are compared with experimental data for the bioreaction dynamics and show satisfactory agreement. The model is used for assessment of the viscosity effect upon the bioreactor performance. A 10-fold viscosity rise results in 2 -fold decrease of $K_{L} a$ and $25 \%$ decrease of the specific gluconic acid production rate. The model allows better understanding of the mechanism of the important bioprocess.
\end{abstract}

\section{Introduction}

Two-phase bioreactor modelling of complex bioreactions coupled with gas-liquid mass transfer and substrate distribution in viscous media presents a challenge for computer-aided process engineering. The accurate description of such systems is hard because inherently imperfect mixing conditions interfere with the complex kinetics of a multi-step bioreaction. An example is gluconic acid production. In this system, both imperfect mixing in the bioreactor and multi-stage kinetics are burdening obstacles.

Gluconic acid is a product widely used in the pharmaceutical, food and chemical production and the biosynthesis is the dominant route for its manufacturing at present (Mislom \& Meers, 1983; Rohr, Kubicek, \& Kominek, 1988). So far two strains, i.e. Gluconobacter oxydans (Nikov, Doneva, \& Vasssilieff, 1988; Velizarov \& Beschkov, 1988) and Aspergillus niger (Liu, Weng, Zhang, Xu, \& Ji, 2003; Mukhopadhyay, Chatterjee, Chaterjee, Banerjee, \& Guha, 2005 ) have been studied. The favoured production process is submerged fermentation by $A$. niger with product yield of $98 \%$ (Singh \& Kumar, 2007). The bioprocess is accompanied by viscosity rise and

Abbreviations: CFD, computational fluid dynamics; DO, dissolved oxygen; RANS, Reynolds-averaged Navier Stokes; STR, stirred tank reactor; UDF, user-defined functions.

* Corresponding author. Tel.: +359 287032 73; fax: +359 28707523.

E-mail address: mixreac@gmail.com (S.D. Vlaev). the culture is known to require high oxygen demand (Atkinson \& Mavituna, 1983). The process design justifies detailed examination of the bioreaction conditions and the local fluid dynamic effects and presents interest for bioprocess simulation.

Models for gluconic acid production by A. niger strain have been proposed. Both bioreaction kinetics and fluid flow models have been accounted for.

The bioreaction kinetics has been examined by Znad, Blazej, Bales, and Markos (2004). Perfect mixing conditions have been assumed in their study. Two kinetic models, e.g. a Monod-type and a Contois-type ones have been equally applied and found to describe the bioreaction time-course with minor difference. The Monod type is known to account for substrate limitation, while the Contois model accounts for biomass inhibition. However, no evidence of biomass inhibition has been shown by the authors. In fact, it is known that the rate of hyphal growth with fungi always depends on nutrient limitations and the effect is most likely well-expressed by Monod (Papagianni, 2004).

Referring to the hydrodynamic conditions, modelling of the combined fluid dynamic and biological reaction performance has been considered only for the case of airlift reactors (Sikula, Jurascik, \& Markos, 2007; Znad, Bales, \& Kawase, 2004; Znad, Bales, Markos, \& Kawase, 2004). Compartmental (cell) models have been proposed: the backflow cell model has been described as good approximation for airlift columns (Znad, Bales, \& Kawase, 2004; Znad, Bales, Markos, et al., 2004) and the tanks-in-series (cell) model has been proposed for internal airlift bioreactors (Sikula 


\begin{tabular}{|c|c|}
\hline \multicolumn{2}{|c|}{ Nomenclature } \\
\hline$a$ & interfacial area $\left(\mathrm{m}^{-1}\right)$ \\
\hline$B$ & baffle width (m) \\
\hline C & concentration $\left(\mathrm{kg} \mathrm{m}^{-3}\right)$ \\
\hline$C_{\mu}$ & turbulent constant \\
\hline$C^{*}$ & $\begin{array}{l}\text { liquid phase dissolved oxygen saturation concentra- } \\
\text { tion }\left(\mathrm{kg} \mathrm{m}^{-3}\right)\end{array}$ \\
\hline$C_{D}$ & drag coefficient \\
\hline$D$ & impeller diameter (m) \\
\hline$d$ & bubble diameter $(\mathrm{m})$ \\
\hline$F$ & volumetric force $\left(\mathrm{N} \mathrm{m}^{-3}\right)$ \\
\hline$g$ & gravitational acceleration $\left(\mathrm{m} \mathrm{s}^{-2}\right)$ \\
\hline$H$ & stirred bed height $(\mathrm{m})$ \\
\hline $\bar{I}$ & unit tensor \\
\hline$k$ & turbulent kinetic energy $\left(\mathrm{m}^{2} \mathrm{~s}^{-2}\right)$ \\
\hline$K_{L}$ & interfacial mass transfer coefficient (m/s) \\
\hline$K_{S}$ & constant in Eq. (5) $\left(\mathrm{g} / \mathrm{dm}^{3}\right)$ \\
\hline$K_{O}$ & constant in Eq. $(5)\left(\mathrm{g} / \mathrm{dm}^{3}\right)$ \\
\hline$K_{L} a$ & volumetric mass transfer coefficient $\left(\mathrm{s}^{-1}\right)$ \\
\hline$L$ & blade length $(\mathrm{m})$ \\
\hline$N$ & impeller speed $\left(\mathrm{s}^{-1}\right)$ \\
\hline $\mathrm{O}$ & off-bottom clearance (m) \\
\hline$P$ & pressure $(\mathrm{Pa})$ \\
\hline $\operatorname{Re}$ & Reynolds number \\
\hline$T$ & tank diameter $(\mathrm{m})$ \\
\hline$t$ & time $(s)$ \\
\hline$U$ & Reynolds-averaged velocity (m/s) \\
\hline$u_{p}^{\prime}$ & velocity fluctuation $(\mathrm{m} / \mathrm{s})$ \\
\hline $\begin{array}{l}u_{p} \\
V^{*}\end{array}$ & tip velocity \\
\hline W & blade width (m) \\
\hline \multicolumn{2}{|c|}{ Greek symbols } \\
\hline$\alpha_{p}$ & phase volume fraction in Eqs. (6)-(8) \\
\hline$\rho$ & density $\left(\mathrm{kg} \mathrm{m}^{-3}\right)$ \\
\hline$\eta$ & viscosity $\left(\mathrm{kg} \mathrm{m}^{-1} \mathrm{~s}^{-1}\right)$ \\
\hline$\alpha$ & rate parameter in Eq. (4) \\
\hline$\beta$ & reaction rate parameter in Eq. $(4)\left(\mathrm{s}^{-1}\right)$ \\
\hline$\gamma$ & rate constant in Eq. (2) \\
\hline$\delta$ & rate constant in Eq. (3) \\
\hline$\varepsilon$ & energy dissipation rate $\left(\mathrm{m}^{2} \mathrm{~s}^{-3}\right)$ \\
\hline$\lambda$ & rate constant in Eq. $(2)\left(s^{-1}\right)$ \\
\hline$\mu$ & specific growth rate $\left(\mathrm{s}^{-1}\right)$ \\
\hline & maximum specific growth rate $\left(\mathrm{s}^{-1}\right)$ \\
\hline$\varphi$ & rate constant Eq. (3) $\left(\mathrm{s}^{-1}\right)$ \\
\hline $\bar{\tau}_{p}$ & stress tensor \\
\hline$\theta$ & source term linearization parameter \\
\hline$\phi$ & $\begin{array}{l}\text { parts of the liquid volume performing at the abscissa } \\
\text { parameter value }\left(\mathrm{m}^{3} \mathrm{~m}^{-3}\right)\end{array}$ \\
\hline \multicolumn{2}{|c|}{ Indices } \\
\hline$d$ & dissolved (refers to oxygen) \\
\hline$e$ & effective \\
\hline$i$ & refers to bioreaction species \\
\hline G & gas \\
\hline $\mathrm{L}$ & liquid \\
\hline$p$ & phase \\
\hline$r$ & relative \\
\hline$t$ & turbulent \\
\hline
\end{tabular}

et al., 2007). So far no study has examined this case by using a CFD numerical flow model based on the Navier-Stokes equations. On the other hand, related to a similar subject it has been demonstrated currently in studies of different systems (Norman
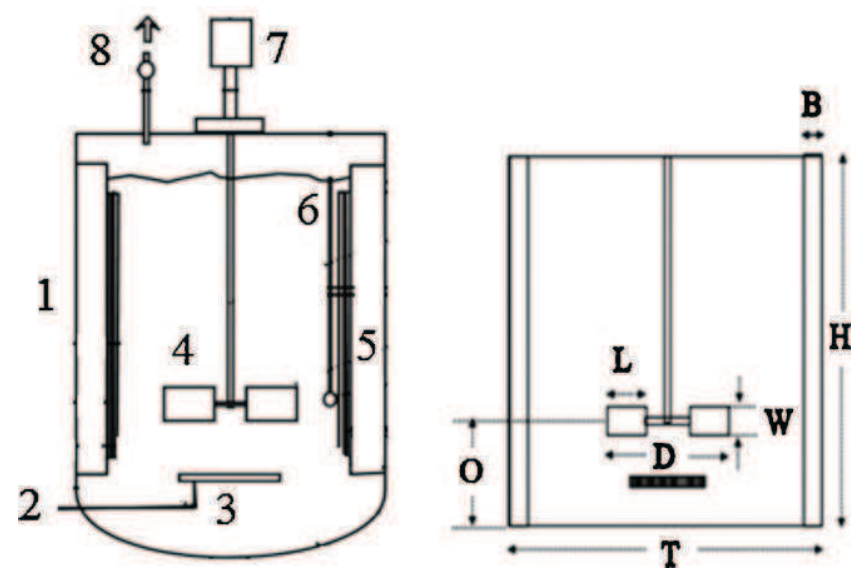

Fig. 1. Bioreactor setup and dimensions: 1 , tank; 2 , air inlet; 3 , sparger; 4 , impeller; 5 , baffles; 6 , probe; 7 , motor; 8 , gas outlet, T-tank diameter, D-impeller diameter, L, W - blade dimensions, C-off bottom clearance, B-baffle width, H-liquid height.

et al., 1993; Schmalzriedt \& Reuss, 1997, and more recently Ghadge, Patwardhan, Sawant, \& Joshi, 2005; Schutze \& Hengstler, 2006) that CFD models ensure improved description of the effect of local flow fields on the bioreaction dynamics; yet the tasks were computer intensive and presented a challenge.

The aim of the present study is to propose a numerical model and solution strategy for the complex two-phase stirred bioreaction system of gluconic acid production by A. niger. In what follows, we apply the set of mathematical equations describing the non-ideal flow with two reactive phases, gas and liquid, to the case of an aerated stirred tank bioreactor for gluconic acid production. The procedure includes: (1) description of the physical chemical system (2) formulation of the kinetic and transport model equations, (3) numerical implementation of the model, and (4) comparison of the numerical results with experimental data.

\section{Experimental bioreactor system}

A view of the bioreactor and its size dimensions is shown in Fig. 1. In view of using the kinetics of the bioreaction reported by Znad, Blazej, et al. (2004), the vessel is the same as the one used in their study. Its diameter is $T=0.185 \mathrm{~m}$ and working volume is $5 \mathrm{dm}^{3}$. The stirrer comprises a six-flat blade turbine impeller and shaft. Its size qualifications are the conventional ones, e.g. impeller diameter $D=T / 3$, off-bottom clearance $C=T / 3$, blade width $W / D=1 / 5$, and blade length $L / D=1 / 4$. Gas is supplied through a $0.05 \mathrm{~m}$ diameter ring sparger located $50 \mathrm{~mm}$ under the impeller.

The fermentation is carried out batch-wise at constant temperature. The liquid containing the glucose substrate is loaded into the vessel. Agitation is started and gas is fed from the sparger to ensure oxygen for the cultivation. Inoculum is introduced in form of a cell suspension of the microorganism $A$. niger and the bioprocess is activated. This moment is indicated as start-up, $t=0$. In parallel to biomass growth, the glucose substrate is being consumed and gluconic acid is generated as a result of the bioreaction.

The bioreaction conditions are as follows: the impeller speed is $300 \mathrm{rpm}$ (tip velocity $V^{*}=1 \mathrm{~m} / \mathrm{s}$ ) and the gas flow rate is $8 \mathrm{dm}^{3} / \mathrm{min}$. At these conditions, the fluid flow at the bioreaction start-up conforms to the turbulent mixing regime $\left(\operatorname{Re}_{L} \approx 2 \times 10^{4}\right.$, where $\operatorname{Re}_{L}=N D^{2} \rho_{L} / \eta_{L}$ is the impeller Reynolds number). At start-up, the bioreactor contains $5 \mathrm{dm}^{3}$ glucose solution and 2\% (by volume) inoculum. The fermentation is started at glucose concentration $150 \mathrm{~g} / \mathrm{dm}^{3}$ and dissolved oxygen concentration corresponding to saturation at $30^{\circ} \mathrm{C}$. During the fermentation, the biomass concentration increases up to $8-10 \mathrm{~g} / \mathrm{dm}^{3}$. Under such conditions, the 
morphology of the fungi is in form of pellets and viscosity is expected to rise starting from $1 \mathrm{mPa}$ s exceeding $10 \mathrm{mPa}$ (Atkinson \& Mavituna, 1983). The bioconversion is completed for $60 \mathrm{~h}$ and gluconic acid concentration reaches $65-70 \mathrm{~g} / \mathrm{dm}^{3}$.

\section{Mathematical model}

\subsection{Kinetic model}

In the present work, the Monod-type model (Znad, Blazej, et al., 2004) is applied due to its reported good description of the product profile under ideal flow conditions.

The following equations are solved:

$r_{X}=\frac{d C_{X}}{d t}=\mu C_{X}$

$r_{S}=\frac{d C_{S}}{d t}=-\gamma \frac{d C_{X}}{d t}-\lambda C_{X}$

$r_{O_{d}}=\frac{d C_{O d}}{d t}=K_{L} a\left(C_{O_{d}}^{*}-C_{O_{d}}\right)-\delta \frac{d C_{X}}{d t}-\varphi C_{X}$

$r_{P}=\frac{d C_{P}}{d t}=\alpha \frac{d C_{X}}{d t}+\beta C_{X}$

where

$\mu=\mu_{m} \frac{C_{S}}{K_{S}+C_{S}} \frac{C_{O d}}{K_{O}+C_{O d}}$

Terms $r_{X}, r_{S}, r_{O d}, r_{P}$ are the rates of cell growth, substrate and oxygen consumption and product generation, respectively. Variables $C_{X}$, $C_{S}, C_{O d}, C_{P}$ are the unknown concentrations of biomass (A. niger), substrate (glucose), dissolved oxygen and product (gluconic acid), respectively, $t$ is time and $\mu_{m}, \alpha, \beta, \gamma, \delta, \lambda, \varphi, K_{S}, K_{O}$ are rate constants governing the cell growth, product accumulation and substrate and oxygen depletion. $K_{L} a$ is the gas-liquid mass transfer coefficient that represents the oxygen mass transfer stage of the bioreaction step of oxygen supply.

It is noteworthy that Eqs. (1)-(4) describe the case of batch gluconic acid production in prefect mixing regime. These equations will be used further in Section 5 to compare the reactor performance corresponding to cases of ideal and imperfect mixing regimes.

\subsection{Flow model}

For the batch gas-liquid system, the two-phase Euler-Euler model has been employed (Ranade, 2003; Kelly, 2008). The governing equations include the mass and momentum conservation equations written separately for each phase. The continuity equation written in general form for phase $p$ is

$\frac{\partial}{\partial t}\left(\alpha_{p} \rho_{p}\right)+\nabla \cdot\left(\alpha_{p} \rho_{p} U_{P}\right)=S_{p}$

where $p$ stands for phase index, $U_{p}$ stands for Reynolds-averaged velocity, $\rho_{p}$ is the phase density and $S_{p}$ is a source term.

The momentum equation in time-averaged form for phase $p$ yields

$$
\begin{aligned}
\frac{\partial}{\partial t}\left(\alpha_{p} \rho_{p} U_{P}\right) & +\nabla \cdot\left(\alpha_{p} \rho_{p} U_{p} U_{P}\right)=-\alpha_{p} \nabla P+\alpha_{p} \rho_{p} g+\nabla \cdot\left(\alpha_{p} \bar{\tau}_{p}\right) \\
& +F_{p, p}-\nabla \cdot\left(\alpha_{p} \rho_{p} \overline{u_{p}^{\prime} u_{p}^{\prime}}\right)
\end{aligned}
$$

where $P$ is pressure, $g$ is gravity acceleration, $\bar{\tau}_{p}$ is the phase $p$ stress tensor, $F_{p, p}$ is the interaction force between the two phases and $u_{p}^{\prime}$ stands for velocity fluctuation.

The variables $\alpha_{p}$ indicate phase $p$ volume fraction ( $p=L$ or $G$ ). They obey to the fractional volume equation:

$\alpha_{L}+\alpha_{G}=1$
Table 1

Bioreaction rate parameters.

\begin{tabular}{ll}
\hline Parameter & Monod type model (Znad, Blazej, et al., 2004) \\
\hline$\mu_{m}\left(\mathrm{~h}^{-1}\right)$ & 0.668 \\
$\alpha$ & 2.92 \\
$\beta\left(\mathrm{h}^{-1}\right)$ & 0.131 \\
$\gamma$ & 2.12 \\
$\lambda\left(\mathrm{h}^{-1}\right)$ & 0.232 \\
$\delta$ & 0.278 \\
$\varphi\left(\mathrm{h}^{-1}\right)$ & $4.87 \times 10^{-3}$ \\
$K_{S}\left(\mathrm{~g} / \mathrm{dm}^{3}\right)$ & 130.9 \\
$K_{O}\left(\mathrm{~g} / \mathrm{dm}^{3}\right)$ & $3.63 \times 10^{-4}$ \\
\hline
\end{tabular}

The viscous stress tensor is related to the mean velocity gradients determined by the equation

$\bar{\tau}_{p}=\eta_{p}\left(\nabla U_{p}+\left(\nabla U_{p}\right)^{T}-(2 / 3)\left(\nabla \cdot U_{p}\right) \bar{I}\right)$, where $\eta_{p}$ is molecular viscosity of phase p. $F_{p, p}$ is determined as $F_{p, p}=(3 / 4) \rho_{L} \alpha_{G} \alpha_{L}\left(C_{D} / d\right)\left(U_{G}-U_{L}\right)\left|U_{G}-U_{L}\right|$, where $d$ is bubble diameter and $C_{D}$ is the drag coefficient.

For calculation of the drag coefficient, the correlation of Schiller and Naumann is used (Clift, Grace, \& Weber, 1978):

$C_{D}=\left\{\begin{array}{l}24\left(1+0.15 R e^{0.687}\right) / R e_{r}, \quad \text { if } R e_{r} \leq 10^{3} \\ 0.44, \quad \text { if } R e_{r}>10^{3}\end{array}\right.$,

where the relative $\operatorname{Re}_{r}=\rho_{L} d\left(U_{G}-U_{L}\right) / \eta_{e}, d$ is bubble size and $\eta_{e}$ is the effective viscosity defined by Eq. (11).

The additional term $\nabla \cdot\left(\alpha_{p} \rho_{p} \overline{u_{p}^{\prime} u_{p}^{\prime}}\right)$ in Eq. (7) accounts for the turbulent contribution to the stress tensor. To close the system, it is complemented by the additional balances for model closure supplied by the solver. In this study, the standard $k-\varepsilon$ model is used and two additional equations balancing turbulent kinetic energy $k$ and rate of energy dissipation $\varepsilon$ for each phase are introduced.

In order to predict the concentrations of the bioreaction components and their distribution, conservation equations for the bioreaction species are included. Written in general form,

$\frac{\partial\left(\alpha_{p} \rho_{p} C_{i}\right)}{\partial t}+\nabla \cdot\left(\alpha_{p} \rho_{p} C_{i} U_{p}\right)=S_{i}$

where $C_{i}$ are the concentrations of the bioreaction (scalar) components $i$, namely, $i=X, S, O_{d}, P$, and $S_{i}$ are the source terms delivered as production terms from Eqs. (1)-(5).

\subsection{Model limitations and parameters}

For the kinetic model Eqs. (1)-(5), the reaction rate parameters summarized in Table 1 are used.

Referring to previous observations (Nikov et al., 1988), the substrate and the product concentrations were seen to have negligible effect on liquid density. In the simulations, constant density was assumed.

In stirred tanks, broth viscosity can be represented by effective viscosity according to the Metzner concept (Elqotbi, Montastruc, Vlaev, \& Nikov, 2006). In turbulent flow, the effective viscosity is determined, as

$\eta_{e}=\eta+\eta_{t}$

where $\eta$ is molecular viscosity and $\eta_{t}$ is turbulent viscosity determined by the equation of $k-\varepsilon$ model, $\eta_{t}=C_{\mu} \rho_{L} k^{2} / \varepsilon_{L}$. Using non-linear regression to the experimental points of $A$. niger fermentation, the molecular viscosity is related to the local biomass concentration $C_{X}\left(\mathrm{~g} / \mathrm{dm}^{3}\right)$ by a power type relationship:

$\eta=\eta_{0}\left(1+C_{X}^{2,26}\right)$,

where $\eta_{0}$ is viscosity of water.

The viscous mixing affects the local dissipation energy distribution and the gas-liquid dispersion pattern and poses variations on 


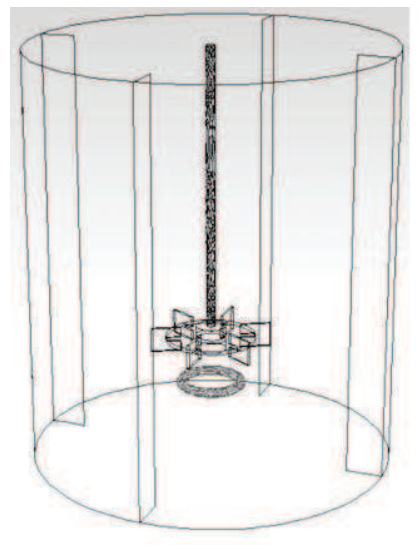

(a)

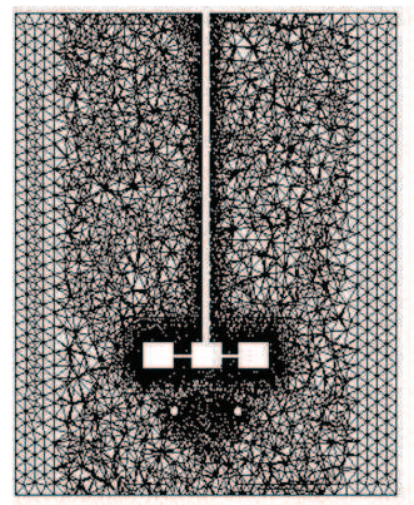

(b)

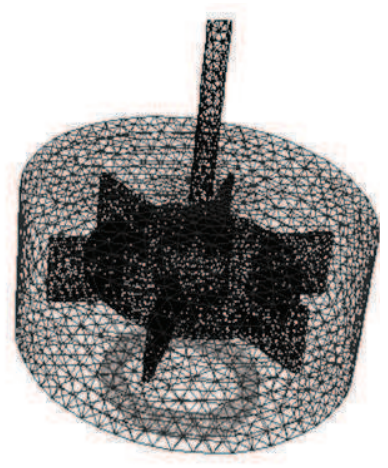

(c)

Fig. 2. Computer rendition of the stirred vessel (a) and views of the grids marking the computational domain for the reactor and the impeller zone (b and c).

the resistance to oxygen transfer. Based on the flow regime of the experiment $\left(\operatorname{Re}_{L}\right)$, oxygen mass transfer was assumed to be dependent on viscous dissipation and was correlated with kinetic energy dissipation rate according to Kawase, Halard, and Moo-Young (1992). The film mass transfer coefficient $\left(K_{L}\right)$ and the specific interfacial area $a$ are determined. Parameter $K_{L}$ is calculated from Eq. (12) related to Higbie's penetration theory (Dhanasekharan, Sanyal, Jain, \& Haidari, 2005):

$K_{L}=C_{1} \sqrt{D_{L}}\left(\frac{\varepsilon_{L} \rho_{L}}{\eta_{L}}\right)^{0.25}$

In this equation, parameter $D_{L}=1.98 \times 10^{-9} \mathrm{~m}^{2} / \mathrm{s}$ is oxygen diffusivity at $20^{\circ} \mathrm{C}$ in water, $\varepsilon_{L}\left(\mathrm{~m}^{2} / \mathrm{s}^{3}\right)$ is the turbulent kinetic energy dissipation rate in the continuous phase, $\rho_{L}\left(\mathrm{~kg} / \mathrm{m}^{3}\right)$ and $\eta_{L}(\mathrm{~Pa} \mathrm{~s})$ are the density and the viscosity of the continuous phase $C_{1}$ is a constant.

The interfacial area $a$ is determined from the gas volume fraction $\alpha_{G}$ and bubble size $d$

$a=\frac{6 \alpha_{G}}{d}$.

It is known that present understanding of breakage and coalescence processes for most of the bioprocess systems is poor (Khopkar \& Ranade, 2010, chap. 15) and this is valid also in A. niger presence. Recent measurement data on bubbles in viscous aerated stirred bioreactors show that the average bubble size between 1 and $4 \mathrm{~mm}$ accounts for more than $70 \%$ of the bubble hold-up (Zhang, Zhang, \& Fan, 2009). Based on previous observations in viscous solutions, in this study effective bubble size $d$ of $2 \mathrm{~mm}$ was assumed.

Eqs. (12) and (13) are used to predict $K_{L} a$ from CFD simulation.

\section{Numerical procedure and solution strategy}

A computational 3D-grid has been elaborated. Unstructured cells were generated. The grid-generation tool Mixsim version 2.0 (Mixsim 2, Fluent, Inc., 2005) was used. Grids with increasing cell number in the range $1.2 \times 10^{5}$ to $3.6 \times 10^{5}$ were examined for invariant solutions. Grid refinement was employed in the proximity of the gas sparger. Solutions at grid density between $3 \times 10^{5}$ and $3.6 \times 10^{5}$ cells did not produce significant differences. The number of cells in this task was set to $3.26 \times 10^{5}$ that corresponded to element size of $2.4 \mathrm{~mm}$. Fig. 2 illustrates the computational domain and the grid density.

The governing equations were solved numerically by Fluent (version 6.23, Fluent Inc., 2005). For partial analysis, Maple (Maple 7 ,
Waterloo Maple Inc., 2001) was used to solve the model for the perfect mixing regime, Eqs. (1)-(5). The impeller motion was modelled using the "inner-outer" solution approach in accordance with the multiple reference frame solution model. The vessel was divided into two parts, a moving frame around the impeller and a stationary frame attached to the vessel wall. User Defined Functions (UDF), sub-set of Fluent were used for completion and adaptation of the source code by the species functions representing the bioreaction. The solver specification included phase-coupled SIMPLE for pressure-velocity coupling. The special discretization was set to QUICK for the volume fraction, to 2nd-order upwind for $k$ and $\varepsilon$, and to 1 st-order upwind for the scalars. The under-relaxation factors of the numerical scheme were set initially to 0.3 for pressure, 0.4 for momentum and 0.2 for the volume fraction with subsequent reduction in the course of computation. The convergence criterion was set to $1 \times 10^{-5}$ for the velocities, to $1 \times 10^{-4}$ for volume fraction and to $10^{-3}$ for the user defined scalars. A reasonable convergence was achieved. The starting time-step size was $10^{-3}$ but it was increased later in the individual stages. An averaged number of iterations corresponding to the separate stages is reported in Table 2.

Boundary conditions were set for solving the governing equations. The velocity of the rotating impeller frame was set to the experimental impeller angular velocity $N=300 \mathrm{rpm}$ corresponding to tip velocity $V^{*}=1 \mathrm{~m} / \mathrm{s}$. For the gas sparger, velocity inlet was specified. The gas entered through the sparger and leaved the stirred vessel through the top surface as a flux. The gas sparger was represented as a ring surface with zero velocity for the continuous phase and inlet velocity of the dispersed phase to conform to the gas flow rate total of $8 \mathrm{dm}^{3} / \mathrm{min}$ by surface integration The component option was used to specify constant inlet gas velocity at unity phase volume fraction (single-phase inlet flow). The top boundary was defined as a velocity inlet with zero velocity of the continuous phase and constant gas linear velocity $5.3 \mathrm{~mm} / \mathrm{s}$ conforming to the gas flow rate and the vessel cross-sectional area (Ranade, 2003). The bioreactor operation was batch. The remaining boundaries were treated as walls with no species fluxes and no gradients (no-slip boundary conditions). These specifications were applied for the scalars - biomass, substrate and the product gluconic acid. Gravitation was fixed at $9.81 \mathrm{~m} / \mathrm{s}^{2}$.

The model validity was examined based on previous experiments and reference data. The hydrodynamic modelling of gas-liquid flow has been validated previously (Gharaibah \& Polifke, 2004). The kinetic model has been checked against experimental data in the kinetic study (Znad, Blazej, et al., 2004). Compared with experimental data, previous numerical data reported by the authors and experienced with RANS and two-phase modelling have 
Table 2

Parameters and equations of the four-step calculation.

\begin{tabular}{|c|c|c|c|c|}
\hline \multirow[t]{2}{*}{ Conditions } & \multicolumn{4}{|l|}{ Stage (iterations) } \\
\hline & $\begin{array}{l}\text { E1 }\left(\sim 10^{4}\right) \\
\text { Flow field steady } \\
N=300 \mathrm{rpm} \\
\eta_{L}=1 \mathrm{mPa} s\end{array}$ & $\begin{array}{l}\text { E2 }(750) \\
\text { D.O. saturation }\end{array}$ & $\begin{array}{l}\text { E3 (13) } \\
\text { Inoculation }^{a}\end{array}$ & $\begin{array}{l}\text { E4 }(7000) \\
\text { Bioreaction }^{\text {a }}\end{array}$ \\
\hline Real time & - & $8 \mathrm{~min}$ & $8 \mathrm{~s}$ & $60 \mathrm{~h}$ \\
\hline Step size $\Delta t(\mathrm{~s})$ & $\Delta t_{F}=0.032$ & $20 \Delta t_{F}$ & $20 \Delta t_{F}$ & $10^{3} \Delta t_{F}$ \\
\hline Equations solved & $\begin{array}{l}\text { Eqs. (6) and (7) } \\
\text { Eqs. (6)-(8) }\end{array}$ & Eqs. (6)-(8), Eq. (9) at $S_{i}=S_{O d}$ Eq. (3) at $C_{X}=0$ & \multicolumn{2}{|c|}{ The complete set Eqs. (6)-(9) and (14 } \\
\hline
\end{tabular}

a Operation.

confirmed the validity of the flow model (Elqotbi et al., 2006; Vlaev, Tonova, Pavlova, \& Elqotbi, 2011).

Considering that the task is computer-intensive, a strategy of step-wise segregated model solution has been adopted: (i) the simulation was carried out in four stages and (ii) multiple iterations were replaced by single ones by linearization.

(i) The simulation stages were selected according to the real stages of the general procedure practiced in fermentation: (1) charging and stirring the substrate solution, (2) switching up air inlet for oxygen saturation, (3) injecting the cells' solution for inoculation, and (4) allowing reaction time for the fermentation. Correspondingly, the computational procedure included (Table 2): (1) solving the flow model Eqs. (6)-(8), (2) generating the dissolved oxygen concentration field by enabling the mass balance for oxygen, Eq. (9) at $i=O_{d}$ with Eq. (3) for no respiration (no cells) at $C_{X}=0$, i.e. $r_{O_{d}}=\left(d C_{O d} / d t\right)=K_{L} a\left(C_{O_{d}}^{*}-C_{O_{d}}\right)$, (3) enabling the biomass balance Eq. (9) at $C_{X} \neq 0$, and (4) solving the complete set of Eqs. (6)-(14). In view of the criteria of saturation valid for stage (2), the mass transfer Eq. (3) was solved at condition of constant coefficient $K_{L} a$ of $0.017 \mathrm{~s}^{-1}$; the solution being converged, in stage $4 K_{L} a$ was allowed to vary according to the prescribed algorithm Eqs. (11)-(13). The model specifications corresponding to the separate bioreactor operations, i.e. time steps, iteration number and solution equations are indicated in the table.

(ii) Being of the first order non-linear type, the set of differential Eqs. (6)-(9) can be solved iteratively by explicit Euler method (Ferziger \& Peric, 1997). While doing the calculation, the conservation equations are integrated in each of the small cell volumes of the domain. To avoid the intensive procedure, the multiple iterations per grid cell were replaced by single iterations. Inherently to the CFD approach, the individual grid cell is perfectly mixed and due to the small step of concentration change within time step $\Delta t=t_{1}-t_{0}$ the species concentrations and the bioreaction growth rate $\mu$ (defined by Eq. (5)) can be considered constant. This allows for small time interval source terms $S_{\theta}$ for species $\theta$ depending on single variables (e.g. $\theta=C_{X}$, $\left.C_{S}, C_{O d}, C_{P}\right)$ to be represented as simplified functions of $\theta$, i.e. $S_{\theta}=K_{0}+K_{1} \theta$ depending on constants $K_{0}$ and $K_{1}$. To carry out the calculation, Eq. (1) is solved and the zero-order term of the series of the exponential function is substituted, thus, $C_{X_{1}}=$ $C_{X_{0}} e^{\mu \Delta t}=C_{X_{0}} \cdot \mu \Delta t$, and $r_{X}=d C_{X} / d t=\mu C_{X}$. Then, the solution of Eq. (1) is used to determine the production or consumption $S_{\theta}$ of the scalar components transported according to the balance Eq. (9). By re-arranging the right hand side of Eqs. (1)-(4), the following equations are obtained:

$$
\begin{aligned}
& S_{X}=\mu C_{X} \\
& S_{S}=-(\gamma \mu+\lambda) C_{X}
\end{aligned}
$$

$S_{O_{d}}=K_{L} a\left(C_{d}^{*}-O_{d}\right)-(\delta \mu+\varphi) C_{X}$

$S_{P}=(\alpha \mu+\beta) C_{X}$

Eqs. (1)-(4) are replaced by Eq. (14) in calculating (9). They were calculated custom-wise by the code UDF option.

\section{Results and discussion}

The concentrations of the bioreaction components predicted by the CFD model are compared with experimental concentrations in Fig. 3(a)-(d). The solid lines illustrate the CFD simulation results. Following the $A$. niger inoculation, the bioreaction starts $(t=0)$ and takes place all the time for $60 \mathrm{~h}$. During the bioprocess, the growth of $A$. niger is initiated and the biomass starts to grow from zero to about $8-10 \mathrm{~g} / \mathrm{dm}^{3}$ (Fig. 3(b)). Accordingly, the glucose substrate is consumed and its concentration falls from $150 \mathrm{~g} / \mathrm{dm}^{3}$ to about $40 \mathrm{~g} / \mathrm{dm}^{3}$ (Fig. 3(a)). Bioproduction takes places and gluconic acid accumulates in the batch starting from zero concentration to $65-75 \mathrm{~g} / \mathrm{dm}^{3}$ (Fig. 3(d)).

The comparison shows good qualitative prediction of the glucose and the gluconic acid concentration profiles by the model. Differences are observed in representing dissolved oxygen and biomass concentrations (Fig. 3(b) and (c)). However, the experimental biomass and dissolved oxygen curves seem also to deviate from smooth behaviour; one observes concentration jumps in the starting hours. The deviations of the model solutions become large by the bioreaction end. This observation could be explained by the fact that the curves in Fig. 3(a)-(d) are cumulative and the solution error tends to accumulate. Besides, the experimental data are based on measurements in a local sample port that is representative only if the reactor operates in complete mixing regime. Using the CFD model, the non-ideality of flow can be assessed by visualization.

To explain the differences in Fig. 3, additional experiments were performed: (i) the bioreaction was simulated in case of a batch perfect mixing regime and (ii) the CFD spatial concentration distributions corresponding to a fixed hour of fermentation were examined.

(i) To simulate the batch perfect mixing case, Eqs. (1)-(5) were solved. These concentrations are illustrated by the dashed lines in Fig. 3. With reference to the biomass and the dissolved oxygen profiles in Fig. 3(b) and (c), respectively, one can see that the model concentrations corresponding to perfect mixing differ substantially from the experimental ones. This difference has been reported also by Znad, Blazej, et al. (2004). Consequently, perfect mixing was not established.

(ii) The bioreaction species' concentration field obtained by the CFD model is visualized in Fig. 4(a)-(d). The case of the 50th hour of fermentation is depicted. At this stage, a perfectly mixed culture in any grid cell should contain $70 \mathrm{~g} / \mathrm{dm}^{3}$ glucose substrate, $10 \mathrm{~g} / \mathrm{dm}^{3}$ biomass, and $65 \mathrm{~g} / \mathrm{dm}^{3}$ gluconic acid, as well 
(a)

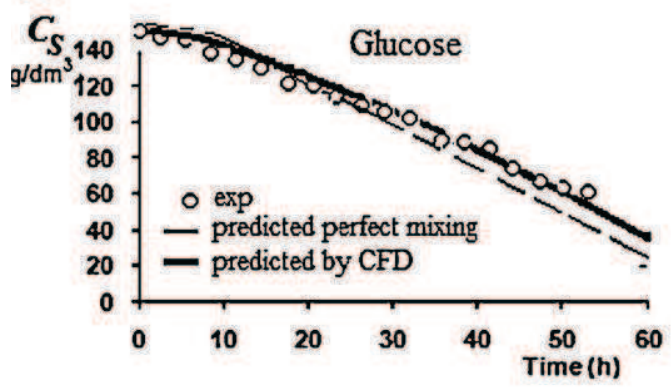

(c)

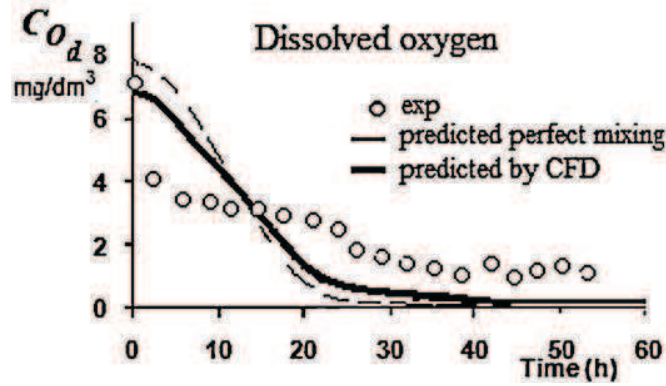

(b)

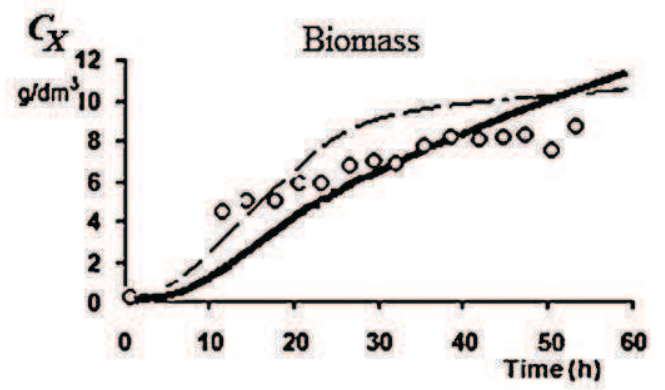

(d)

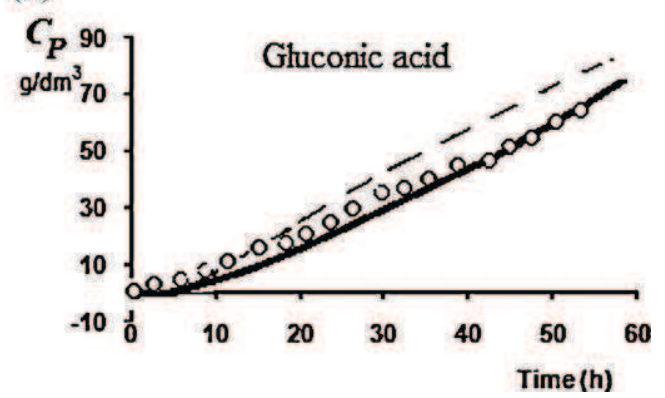

Fig. 3. Comparison of simulated and experimental concentration profiles of (a) glucose, (b) A. niger biomass, (c) dissolved oxygen, and (d) gluconic acid.

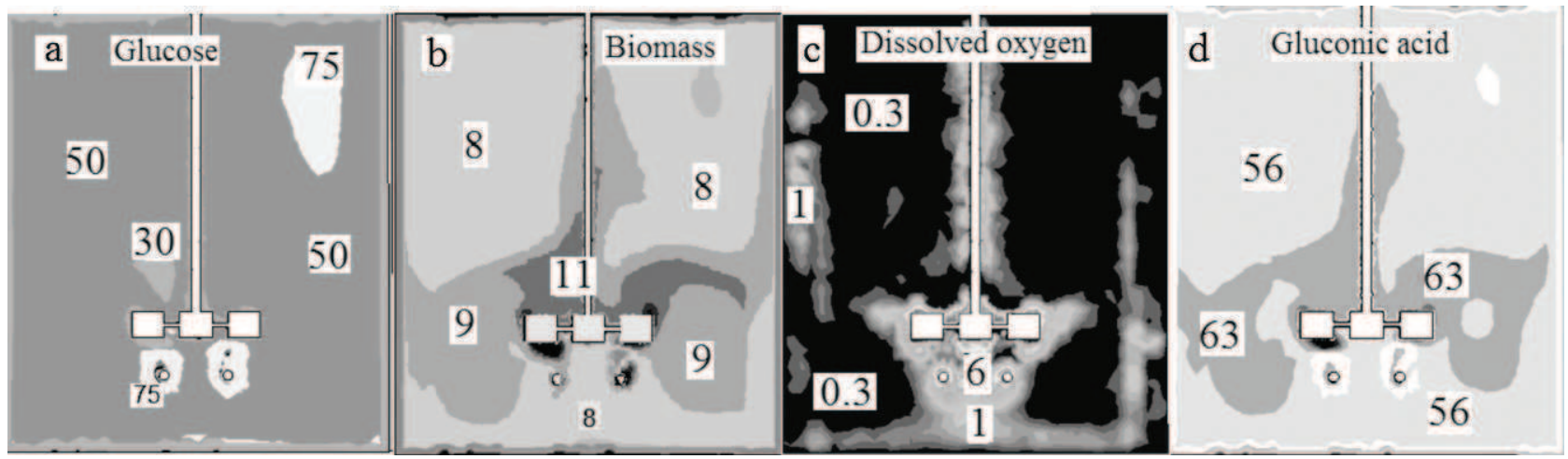

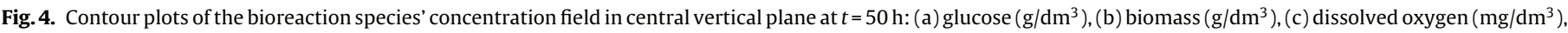
and (d) gluconic acid $\left(\mathrm{g} / \mathrm{dm}^{3}\right)$.

as about $2 \mathrm{mg} / \mathrm{dm}^{3}$ dissolved oxygen. As seen in the figure, in spite of the prolonged time scale of the fermentation, in hours, compared to mixing time of seconds, the fluid concentration appears to be non-uniform and concentration gradients are observed for both the product and the biomass, especially so for the dissolved oxygen. For example, the local glucose concentration in Fig. 4(a) varies in zones of $30 \mathrm{~g} / \mathrm{dm}^{3}, 50 \mathrm{~g} / \mathrm{dm}^{3}$ and $75 \mathrm{~g} / \mathrm{dm}^{3}$, the local biomass in Fig. 4(b) varies in zones between $8 \mathrm{~g} / \mathrm{dm}^{3}$ and $11 \mathrm{~g} / \mathrm{dm}^{3}$ and the local gluconic acid in Fig. 4(d) spreads between $56 \mathrm{~g} / \mathrm{dm}^{3}$ and $63 \mathrm{~g} / \mathrm{dm}^{3}$ corresponding to a 3-fold local dissolved oxygen variation in the bioreactor bulk (Fig. 4(c)) Evidently, the mixing pattern conforms to nonideal mixing regime with subsequent effect on the averaging of data.

The results described before will imply better understanding of the bioreactor performance. The simulation results have been used to study the flow field and the oxygen mass transfer during the bioreaction. A. niger fermentation of glucose is growth associated and oxygen dependent. During the fermentation, the biomass accumulates and causes increase of the culture consistency. The viscosity increases and affects the local flow field dissipation energy distribution and the gas-liquid dispersion pattern. Both variables pose variations on the resistance to oxygen transfer. The case was analyzed by CFD. The portions of the vessel volume $(\varnothing)$ of stagnant flow and local $K_{L} a$ were determined. Table 3 and Fig. 5(a)-(c) illustrate the results obtained for a step-wise viscosity rise from $1 \mathrm{mPa}$ s to $10 \mathrm{mPa}$. The viscosity elevation corresponds to different stages of the bioreaction evolution.

Table 3 shows the portion of bulk volume of the individual phases that exhibit linear velocity less than $1 \%$ of tip velocity $V^{*}$ (e.g. $\sim 0.01 \mathrm{~m} / \mathrm{s}$ ). The results show that the portion of stagnant liquid increases up to $30 \%$. In parallel, parameter $K_{L} a$ decreases.

Table 3

Variation of stagnant zones' volume versus viscosity stepwise increase.

\begin{tabular}{llllll}
\hline Case no. & 1 & 2 & 3 & 4 & 5 \\
\hline Viscosity & $\mu_{\mathrm{o}}$ & $2.5 \mu_{\mathrm{o}}$ & $5 \mu_{\mathrm{o}}$ & $7.5 \mu_{\mathrm{o}}$ & $10 \mu_{\mathrm{o}}$ \\
$\begin{array}{c}\text { Stagnant volume } \\
\quad \text { continuous phase (\%) }\end{array}$ & 2.1 & 2.3 & 5.1 & 9.2 & 32.5 \\
$\begin{array}{c}\text { Stagnant volume } \\
\quad \text { dispersed phase (\%) }\end{array}$ & $10^{-3}$ & $10^{-3}$ & $10^{-2}$ & 0.035 & 0.26 \\
\hline
\end{tabular}


(a)

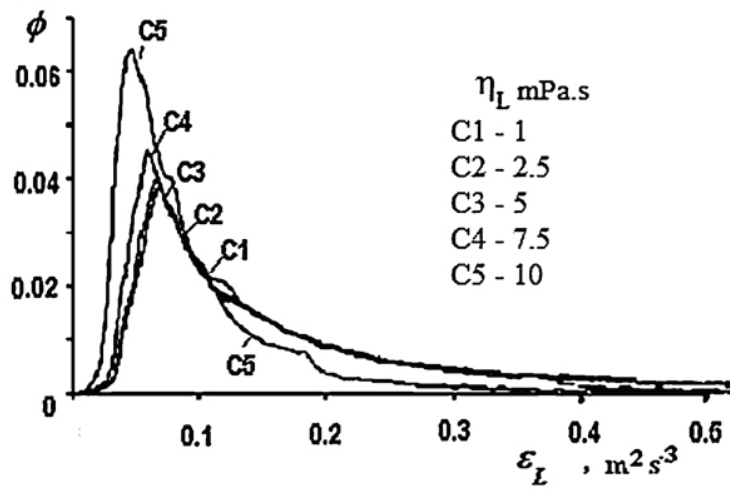

(b)

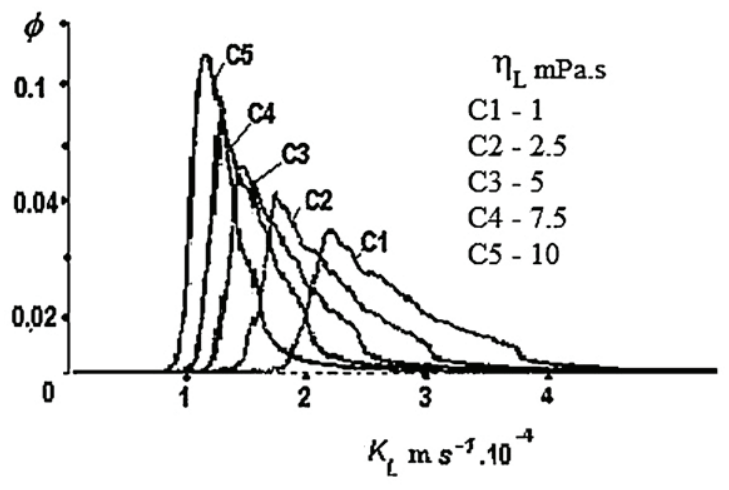

(c)

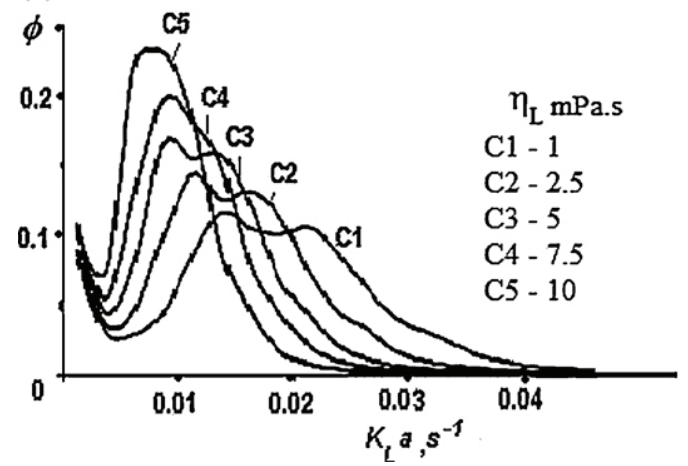

Fig. 5. Variation of the parameters $\varepsilon_{L}(\mathrm{a}), K_{L}(\mathrm{~b}), K_{L} a$ (c) volumetric distribution ( $\varnothing$ ) corresponding to stepwise viscosity increase: curves $\mathrm{C} 1-\mathrm{C} 5$ correspond to viscosity $\mu_{0}, 2.5 \mu_{0}, 5 \mu_{0}, 7.5 \mu_{0}$, and $10 \mu_{\mathrm{o}}$ (where $\mu_{\mathrm{o}}=1 \mathrm{mPa}$ s is valid for water).

Fig. 5(a)-(c) illustrates the volumetric distributions of $\varepsilon_{L}, K_{L}$ and $K_{L} a$ corresponding to various viscosities. One can observe the decrease of the interfacial and the volumetric mass transfer coefficients, $K_{L}$ and $K_{L} a$, and also compare their volumetric spread (estimated as parts of liquid volume (i) performing at $K_{L} a_{i}$ ). Referring to Fig. 5(a), $\varepsilon_{L}$-values $0.1-0.2 \mathrm{~m}^{2} / \mathrm{s}^{3}$ dominate at the start-up of the bioreaction (case $\mathrm{C} 1$ ) and decrease to $0.05-0.1 \mathrm{~m}^{2} / \mathrm{s}^{3}$ by the bioreaction end (case C5). Similarly in Fig. 5(b), cases C1 and C5 compared, the liquid film coefficient $K_{L}$ decreases 2-fold from about average $3 \times 10^{-4}$ to $1.5 \times 10^{-4} \mathrm{~m} / \mathrm{s}$. Average $K_{L} a$ is about $0.023 \mathrm{~s}^{-1}$ at the bioreaction start (case $\mathrm{C} 1$ ) and $K_{L} a$ distribution is rather spread; further it decreases more than 2-fold to average $10^{-2} \mathrm{~s}^{-1}$ and exhibits a narrow distribution when viscosity rises 10 -fold and the biofluid becomes more stagnant (case C5). Compared with the cases of viscous solutions measured by Kelly et al. (2004), the oxygen transfer coefficients of $K_{L} a \sim 0.01 \mathrm{~s}^{-1}$ obtained in this study are similar and confirm the simulation potential of the CFD model.

The change of mass transfer rate corresponds to variable oxygen delivery in the microbial cells and explains the bioreaction time-course observed in Fig. 3(a)-(d). In Fig. 3(a)-(d), comparing the solid lines describing imperfect mixing segregated flow and the dashed lines corresponding to perfect mixing, one observes larger slopes for the dashed curves. Evidently, the CFD model solution exhibits lower slopes and thus lower rates of bioreaction, e.g. low substrate and oxygen consumption rate and low product and biomass generation. Lower slopes of the bioreaction time-course curve mean hindered bioreaction due to some obstacle. Because the bioreaction is extremely sensitive to oxygen supply, the effect of bioreaction delay should be due to the decrease of oxygen transfer in view of increasing broth viscosity. A rough estimation of the slopes in Fig. 3(d) yields the gluconic acid production rate as $\Delta C_{P} / \Delta t$ in $\mathrm{g} \mathrm{dm}^{-3} \mathrm{~h}^{-1}$. With regard to the range of extensive production (5-40 h), we determined the values $1.71 \mathrm{~g} \mathrm{dm}^{-3} \mathrm{~h}^{-1}$ and $1.28 \mathrm{~g} \mathrm{dm}^{-3} \mathrm{~h}^{-1}$ for perfect mixing (dashed line) and CFD model (solid line), respectively. Consequently, the non-ideal flow accounts for a $25 \%$ production rate decrease.

The conditions uncovered by the CFD model of this study may explain the discrepancy of data observed previously by Znad, Blazej, et al. (2004) and Mukhopadhyay et al. (2005).

\section{Conclusion}

The two-phase gluconic acid production in a stirred bioreactor has been modelled using three dimensional CFD software. The bioproduction time-course was simulated. The model provides good description of glucose substrate concentration and the bioproduct concentration versus time. The simulation is based on the approach of (1) stepwise solution resolving first the fluid flow field, further imposing oxygen mass transfer and bioreaction, and (2) a segregated solution replacing multiple iterations per grid cell with single iteration. The solution is stable and requires less computational effort. Satisfactory agreement between numerical results and experimental data is obtained.

The CFD model allows better understanding of the mechanism of the important bioprocess. Comparing different models, it is shown that the perfect mixing model is largely inadequate to predict the bioreactor dynamics. The CFD visualization of the concentration fields of the bioreaction species appear non-uniform and the image shows that the flow field in the bioreactor corresponds to imperfect mixing. The model is used to study the oxygen mass transfer in the highly viscous culture. It is shown that the mass transfer coefficient $K_{L} a$ decreases significantly by biomass growth. The $K_{L} a$ decrease is accompanied by reduction of gluconic acid production rate. We have estimated that a 10 -fold viscosity rise results in 2fold decrease of $K_{L} a$ and $25 \%$ decrease of the specific production rate. The CFD results can be used for extrapolation.

\section{Acknowledgements}

The study has been supported by a DRRT grant and the DRT of the region NORD-PAS de CALAIS, Contract CPER 2000-06/AXE 1. SDV is grateful to USTL board for a visiting fellowship grant in support of the study.

\section{References}

Atkinson, B., \& Mavituna, F. (1983). Biochemical engineering and biotechnology handbook. UK: McMillan Publ.

Clift, R., Grace, J. R., \& Weber, M. E. (1978). Bubbles, drops and particles. San Diego: Academic Press.

Dhanasekharan, K., Sanyal, J., Jain, A., \& Haidari, A. (2005). A generalized approach to model oxygen transfer in bioreactors using population 
balances and computational fluid dynamics. Chemical Engineering Science, 60 , 213-218.

Elqotbi, M., Montastruc, L., Vlaev, S. D., \& Nikov, I. (2006). Shear analysis of mixing reactors - Verification of the CFD approach. In F. Magelli, G. Baldi, \& A. Brucato (Eds.), Proc 12th Eur. conf. mixing (pp. 479-486). AIDIC: Bologna.

Ferziger, J. H., \& Peric, M. (1997). Computational methods for fluid dynamics. Berlin: Springer.

Ghadge, R. S., Patwardhan, A. W., Sawant, S. B., \& Joshi, J. B. (2005). Effect of flow pattern on cellulase deactivation in stirred tank bioreactors. Chemical Engineering Science, 60, 1067-1083.

Gharaibah, E., \& Polifke, W.(2004). A numerical model of dispersed two phase flow in aerated stirred vessels. In M. Sommerfeld (Ed.), Bubbly flows: Analysis, modelling and calculation (pp. 295-306). Berlin: Springer.

Kawase, Y., Halard, B., \& Moo-Young, M. (1992). Liquid-phase mass transfer coefficients in bioreactors. Biotechnology and Bioengineering, 39, 1133-1140.

Kelly, W. J. (2008). Using CFD to characterize and improve bioreactor performance. Biotechnology and Applied Biochemistry, 49, 225-238.

Kelly, S., Grimm, L. H., Hengstler, J., Schultheis, E., Krull, R., \& Hempel, D. (2004). Agitation effects on submerged growth and product formation of $A$. niger. Bioprocess and Biosystems Engineering, 26, 315-323.

Khopkar, A. R., \& Ranade, V. V. (2010). Stirred vessels: Computational modeling of multiphase flows and mixing. Chemical Engineering in the Pharmaceutical Industry: RED to Manufacturing, 269-297. http://dx.doi.org/10.1002/9780470882221

Liu, J. Z., Weng, L. P., Zhang, Q. L., Xu, H., \& Ji, L. N. (2003). A mathematical model for gluconic acid fermentation by A. niger. Biochemical Engineering Journal, 14, 137-141.

Mislom, P. E., \& Meers, J. L. (1983). Gluconic and itaconic acids. In M. Moo-Young H. W. Blanch, S. Drew, \& D. Wang (Eds.), Comprehensive biotechnology (pp. 681-700). Oxford: Pergamon Press.

Mukhopadhyay, R., Chatterjee, S., Chaterjee, B. P., Banerjee, P. C., \& Guha, A. K. (2005). Production of gluconic acid from whey by free and immobilized A. niger. International Dairy Journal, 15, 299-303.

Norman, H., Morud, K., Hjertager, B. H., Trägärd, C., Larson, G., \& Enfors, S. O. (1993). CFD modelling and verification of flow and conversion in a $1 \mathrm{~m}^{3}$ bioreactor. In A. W. Nienow (Ed.), Proc 3d int. conf. on bioreactor and bioprocess fluid dynamics (pp. 241-258). Cranfield: MEP/BHR Group.
Nikov, I., Doneva, G., \& Vasssilieff, C. (1988). Catalytic and biocatalytic oxidation of glucose to gluconic acid in a modified three-phase reactor. In Proc. 2nd int. symp. catalysis in multiphase reactors Toulouse, France, (p. 383).

Papagianni, M. (2004). Fungal morphology and metabolite production in submerged mycelial processes. Biotechnology Advances, 22, 189-259.

Ranade, V. V. (2003). Computational flow modeling for chemical reactor engineering. San Diego: Academic Press.

Rohr, M., Kubicek, C. P., \& Kominek, J. (1988). Gluconic acid. In H. J. Rehm, \& G. Reed (Eds.), Biotechnology (pp. 455-465). Verlag Chemie: Weinheim, p. 3.

Schmalzriedt, S., \& Reuss, M. (1997). Application of CFD to simulations of mixing and biotechnical conversion process in stirred tank bioreactors. Récent Progrès Génie des Procédés, 11, 171-178.

Schutze, J., \& Hengstler, J. (2006). Assessing aerated bioreactor performance using CFD. In F. Magelli, G. Baldi, \& A. Brucato (Eds.), Proc 12th Eur. conf. mixing (pp. 439-446). Bologna: AIDIC.

Singh, O. V., \& Kumar, R. (2007). Biotechnological production of gluconic acid: Future implications. Applied Microbiology and Biotechnology, 75, 713-722.

Sikula, I., Jurascik, M., \& Markos, J. (2007). Modeling of fermentation in an internal loop airlift bioreactor. Chemical Engineering Science, 62, 5216-5221.

Velizarov, S., \& Beschkov, V. (1988). Biotransformation of glucose to free gluconic acid by Gluconobacter oxydans: Substrate and product inhibition situations. Process Biochemistry, 33(5), 527-534.

Vlaev, S. D., Tonova, K., Pavlova, K., \& Elqotbi, M. (2011). Bioprocessing of EPS: CFD optimization of bioreactor conditions. In E. N. Pistikopoulos, M. C. Georgiadis, \& A. C. Kokossis (Eds.), 21st Eur. symp. CAPE-ESCAPE 21 (Part B) (pp. 1411-1415). Amsterdam: Elsevier.

Zhang, H., Zhang, K., \& Fan, Sh. (2009). CFD simulation coupled with population balance equations for aerated stirred bioreactors. Engineering in Life Sciences, 9(6), 421-430.

Znad, H., Bales, V., \& Kawase, Y. (2004). Modeling and scale up of airlift bioreactor Computers and Chemical Engineering, 28, 2765-2777.

Znad, H., Bales, V., Markos, J., \& Kawase, Y. (2004). Modeling and simulation of airlift bioreactors. Biochemical Engineering Journal, 21, 73-81.

Znad, H., Blazej, M., Bales, V., \& Markos, J. (2004). A kinetic model for gluconic acid production by Aspergillus niger. Chemical Papers, 58(1), 23-28. 